Proc. 15th Int. Conference on Defects Recognition, Imaging and Physics in Semiconductors, Warsaw, Poland 2013

\title{
Output Estimation of Concentrator Photovoltaic Using Mappings of Environmental Factors and Performance Ratio
}

\author{
K. Nomura ${ }^{a, *}$, Y. OtA ${ }^{a}$, T. Minemoto ${ }^{b}$ And K. NishiokA ${ }^{a}$ \\ ${ }^{a}$ Faculty of Engineering, University of Miyazaki, 1-1 Gakuen Kibanadai-nishi Miyazaki 889-2192, Japan \\ ${ }^{b}$ College of Science and Engineering, Ritsumeikan University, 1-1-1 Nojihigashi, Shiga 525-8577, Japan \\ Estimation of the output energy of concentrator photovoltaic system is difficult, because the output energy of \\ concentrator photovoltaic system installed outdoors is influenced by various environmental factors. A new method \\ to estimate the output energy is proposed using a contour map of environmental factors. The contour map of \\ estimated output energy was quite similar to that of experimentally-measured output energy. The error ratio of \\ the estimated output energy to the actual output energy was only $-0.14 \%$. The result indicates that this method \\ is useful to estimate the output energy of CPV systems.
}

DOI: $10.12693 /$ APhysPolA.125.1021

PACS: 42.79.Ek, 88.40.jp

\section{Introduction}

In recent years, multijunction solar cells have attracted increasing attention for application in concentrator photovoltaic (CPV) systems owing to their very high conversion efficiency [1]. Multijunction solar cells consisting of InGaP, InGaAs, and Ge layers are recognized as superhigh efficiency cells and are used for space application. Now, a metamorphic InGaP/GaAs/InGaNAs triple-junction solar cell has reportedly delivered a conversion efficiency of $43.5 \%$ at 925 suns $\left(925 \mathrm{~kW} / \mathrm{m}^{2}\right.$, AM1.5D) [2]. Light concentration is one of the most important factors for the development of an advanced PV system using high-efficiency solar cells. High-efficiency multijunction cells under high light concentration have been investigated for terrestrial application [3, 4].

Characteristics of $\mathrm{CPV}$ are more sensitive to environmental factor as compared to flat-plate PV system because CPV systems use lens and multijunction solar cells [5]. CPV systems have power ratings determined by their energy conversion efficiency under standard test conditions (STC; incident direct solar irradiance: $1 \mathrm{~kW} / \mathrm{m}^{2}$, solar spectrum distribution: AM1.5D and cell temperature: $25^{\circ} \mathrm{C}$ ) and the total area of CPV arrays. The estimated output energy from the power rating might be significantly different from the output energy at an outdoor location. Thus, CPV system should be rated with energy rating given by the actual electrical output, rather than by the energy conversion efficiency measured under the STC. However, the impact of the outdoor environment on the output energy is not fully understood, especially, the influence of the spectral irradiance distribution of solar radiation. The spectral distribution has a strong influence on the output current of

* corresponding author; e-mail: ta13014@student.miyazaki-u.ac.jp
CPV system because the system uses the multijunction solar cells [5].

To date, we have analyzed the performance of PV systems at outdoor locations using contour maps centered on the cell temperature $\left(T_{\text {cell }}\right)$ and the index for the spectral irradiance distribution, average photon energy (APE) [6]. The impact of $T_{\text {cell }}$ and APE on the performance of PV system was clearly shown by the contour maps.

In this study, we propose a method for the estimation of the output energy of CPV system using contour maps of environmental factors. The advantages of this method are a wide range of environmental conditions categorized by APE and $T_{\text {cell }}$ are taken into account. Besides, the influence of the spectral irradiance distribution which is especially useful in estimating the output energy of CPV system with spectral sensitivity is also being considered. The energy production of CPV system was estimated using the contour maps in order to demonstrate the validity of the proposed method.

\section{Experimental procedure}

Figure 1 shows a $14 \mathrm{~kW}$ CPV system (Daido Steel Co. Ltd.) installed in University of Miyazaki. Panel area was $7 \mathrm{~m} \times 10 \mathrm{~m}$. A Fresnel lens $(160 \mathrm{~mm} \times 160 \mathrm{~mm})$ concentrates sunlight and the concentrated light was irradiated onto the InGaP/InGaAs/Ge triple-junction solar cell $(7 \mathrm{~mm} \times 7 \mathrm{~mm})$. A CPV module was fabricated by connecting 25 lens-cell pairs in series. The $14 \mathrm{~kW} \mathrm{CPV}$ system was composed of 96 modules.

As meteorological data, we measured direct normal irradiance (DNI) every $1 \mathrm{~min}$. Direct solar spectra with the wavelength range from 350 to $1050 \mathrm{~nm}$ were recorded every 1 min by a spectroradiometer (MS700, EKO) with a collimation tube (aperture angle: $\pm 2.5^{\circ}$ ).

APE is an index that indicates a spectral irradiance distribution [6]. A value of APE was calculated from measured value of spectral irradiance by dividing the integrated irradiance with the integrated photon flux density, yielding the average energy per photon $(\mathrm{eV})$ : 


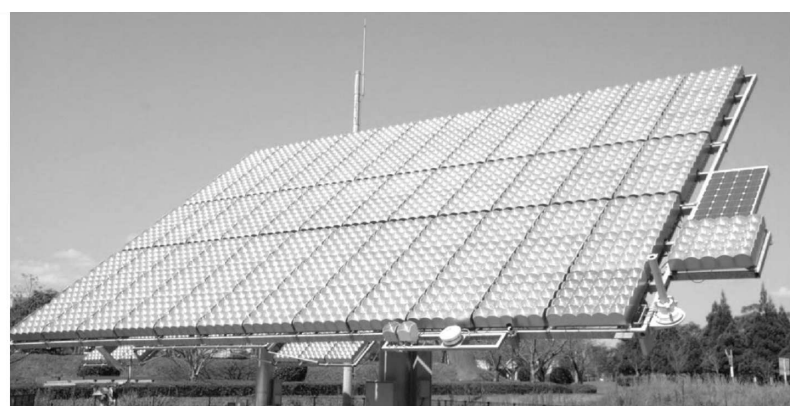

Fig. 1. $14 \mathrm{~kW} \mathrm{CPV} \mathrm{system} \mathrm{installed} \mathrm{in} \mathrm{University} \mathrm{of}$ Miyazaki.

$$
\mathrm{APE}=\frac{\int_{a}^{b} E(\lambda) \mathrm{d} \lambda}{q \int_{a}^{b} \Phi(\lambda) \mathrm{d} \lambda},
$$

where $q$ is the electronic charge, $E$ - spectral irradiance and $\Phi$ - the spectral photon flux density, respectively. For the limitation of our measurement system, $a$ and $b$ were set to 350 and $1050 \mathrm{~nm}$, respectively. The APE value for the standard solar spectrum (AM1.5D) calculated with this range is $1.85 \mathrm{eV}$. The solar spectra with different APE values (1.79-1.96 eV) are shown in Fig. 2. The spectral irradiance was normalized with the irradiance at $560 \mathrm{~nm}$ for each spectrum. The spectral irradiances in short and long wavelength regions increased and decreased respectively with increasing the APE value without crossover.

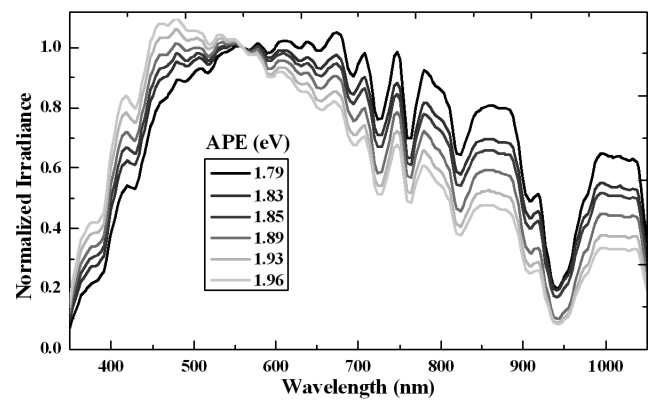

Fig. 2. Solar spectra with APE values from 1.79 to $1.96 \mathrm{eV}$.

Figure 3 shows a flow chart of how the contour graphs were made from APE, $T_{\text {cell }}$, output energy, and DNI pieces of data. The methodology is as follows:

(1) The data of temperature of solar cell $\left(T_{\text {cell }}\right)$, DNI for $1 \mathrm{~m}^{2}$, output energy $\left(P_{\text {out }}\right)$ of the system which has nominal output power of $14 \mathrm{~kW}$, and the spectral irradiance distribution at the analysis period are prepared. The two-dimensional arrays for DNI and for $P_{\text {out }}$ are prepared. The arrays for $P_{\text {out }}$ and DNI have APE (1.70$1.90 \mathrm{eV}, 0.01 \mathrm{eV}$ step $)$ and $T_{\text {cell }}\left(0-80^{\circ} \mathrm{C}, 5^{\circ} \mathrm{C}\right.$ step $)$ for column and row, respectively.

(2) The following steps are repeated for the data measured every 1 min from November 2011 to April 2012 (first period) and November 2012 to 2013 April (second period). Here, the data with DNI higher than

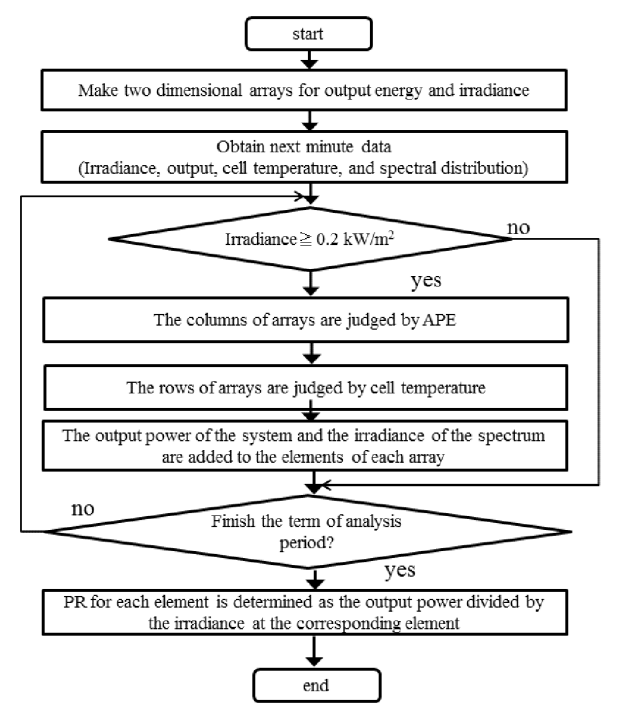

Fig. 3. Flow chart of how the contour graphs were made.

$0.20 \mathrm{~kW} / \mathrm{m}^{2}$ were used and lower performance of system at low DNI was omitted. The reason why we used irradiance higher than $0.20 \mathrm{~kW} / \mathrm{m}^{2}$ was the fluctuation of output voltage, which resulted in fluctuation of the maximum power point tracking (MPPT) control of the inverter.

(a) APE of spectrum is determined by the spectrum distribution.

(b) The columns of both $P_{\text {out }}$ and DNI arrays for the spectrum are indexed by APE.

(c) The rows of both $P_{\text {out }}$ and DNI arrays for the spectrum are indexed by $T_{\text {cell }}$. Then, the elements of the arrays for the spectrum are determined.

(d) $P_{\text {out }}$ of the system and DNI of the spectrum are added to the elements of each array.

(3) Performance ratio (PR) for each element is determined as $P_{\text {out }}$ divided by DNI at the corresponding element. PR is given as follows:

$$
\mathrm{PR}=\frac{\frac{P_{\text {out }}(\mathrm{kW})}{\mathrm{DNI}\left(\mathrm{kW} / \mathrm{m}^{2}\right)}}{\frac{14(\mathrm{~kW})[\mathrm{rated} \text { power of CPV system }]}{1\left(\mathrm{~kW} / \mathrm{m}^{2}\right)[\text { DNI for rating }]}} .
$$

The output energy of a CPV system at an outdoor location under an integrated irradiance is formulated as

$$
\begin{aligned}
& I_{\mathrm{rr}}\left(\mathrm{kWh} / \mathrm{m}^{2}\right) \times A\left(\mathrm{~m}^{2}\right) \times \eta @ \mathrm{STC} \times \mathrm{PR} \\
& \quad=\text { output energy }(\mathrm{kWh}),
\end{aligned}
$$

where $A\left(\mathrm{~m}^{2}\right)$ is the area of the array, $\eta @ \mathrm{STC}$ is the conversion efficiency under the STC, $I_{\mathrm{rr}}$ is the integrated irradiance, and output energy is the energy output of the CPV system, respectively.

The procedures to create the contour plots and estimate the annual energy production for CPV system are as follows:

1. A contour map of PR is made from the measurement data of the first period. Two-dimensional ar- 
rays for the incident irradiance and the output energy are prepared. The incident irradiance and the output energy are classified into the APE (1.70$1.90 \mathrm{eV}, 0.01 \mathrm{eV}$ step $)$ and $T_{\text {cell }}\left(0-80^{\circ} \mathrm{C}, 5^{\circ} \mathrm{C}\right.$ step $)$, respectively. The incident irradiance and the output energy are added to the elements of each array. Contour maps of the integrated irradiance and the integrated energy were obtained from this procedure. The PR for each element is determined as the energy divided by the irradiance at the corresponding element, which provides a contour map of the PR.

2. The PR contour maps are assumed to be unchanged for each period.

3. The output energy for second period is estimated using the PR contour map.

4. The output energy of second period is verified with the experimentally measured output energy of second period.

\section{Results and discussion}

Figure $4 \mathrm{a}$ and $\mathrm{b}$ shows the irradiation $\left(\mathrm{kWh} / \mathrm{m}^{2}\right)$ during the second period and the PR (\%) of the CPV system for the first period. Using these maps, the output energy during the second period was estimated with Eq. (3). Figure $4 \mathrm{c}$ and $\mathrm{d}$ shows the estimated and actual output energies of the CPV system in the second period.

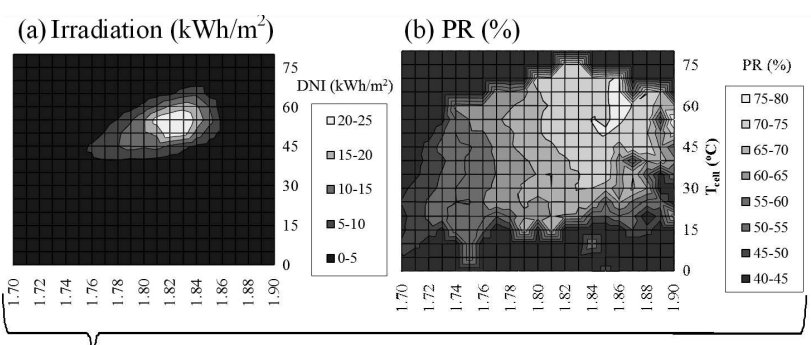

Estimation of output energy using equation (3)

(c) Estimated output energy (kWh) (d) Actual output energy (kWh)

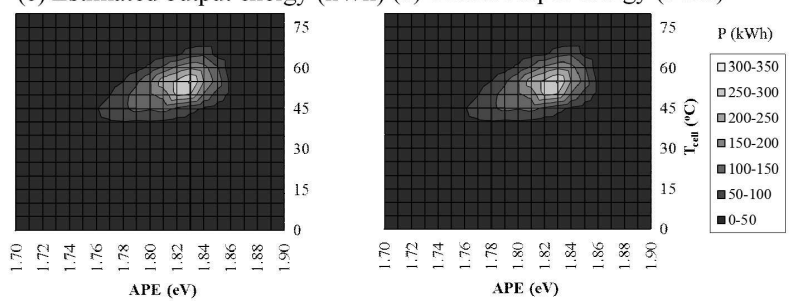

Fig. 4. Comparison of estimated and actual output energies of CPV system. (a) Irradiation $\left(\mathrm{kWh} / \mathrm{m}^{2}\right)$ during the second period. (b) PR (\%) of the CPV system for the first period. (c) Estimated output energy of the CPV system in the second period. (d) Actual output energy of the CPV system in the second period. Estimated energy: $5908 \mathrm{kWh}$, actual energy: $5916 \mathrm{kWh}$, degree of coincidence: $99.86 \%$, error: $-0.14 \%$.
From the PR map of Fig. $4 \mathrm{~b}$, it can be seen that the $\mathrm{PR}$ of the CPV system is strongly influenced by the APE value. The characteristic of CPV system is sensitive to the spectrum of incident light because the system uses multijunction solar cells.

In order to derive the estimated output energy map, we used the PR map of the same season because APE value is influenced by changing season. The contour map of the estimated output energy was quite similar to that of the actual output energy. The amount of the estimated output energy was $5908 \mathrm{kWh}$, meanwhile. The amount of the actual output energy was $5916 \mathrm{kWh}$. The error ratio of the estimated output energy to the actual output energy was only $-0.14 \%$. The proposed method using environmental factor contour and APE maps can be considered to be a useful method for the estimation of the CPV energy production.

\section{Conclusion}

A method was proposed for the estimation of the output energy of CPV system using contour maps centered on APE and $T_{\text {cell }}$. The advantages of this method are a wide range of environmental conditions categorized by APE and $T_{\text {cell }}$ taken into account. Besides, the influence of the spectral irradiance distribution which is especially useful in estimating the output energy of $\mathrm{CPV}$ system with spectral sensitivity is also being considered. To demonstrate the validity of the proposed method, the output energy of the CPV system was estimated. The contour map of the estimated output energy was quite similar to that of the actual output energy. The error ratio of the estimated output energy to the actual output energy was only $-0.14 \%$. The result indicates that the proposed method using contour maps is useful for the estimation of the energy production of CPV system.

\section{References}

[1] M. Yamaguchi, Sol. Energy Mater. Sol. Cells 75, 261 (2003).

[2] V. Sabnis, H. Yuen, M. Wiemer, AIP Conf. Proc. 1477, 14 (2012).

[3] K. Araki, M. Kondo, H. Uozumi, N.J. Ekins-Daukes, T. Egami, M. Hiramatsu, Y. Miyazaki, M. Yamaguchi, Sol. Energy Mater. Sol. Cells 90, 3320 (2006).

[4] K. Araki, T. Yano, Y. Kuroda, Opt. Expr. 18, A53 (2010).

[5] I. Antón, C. Domínguez, M. Victoria, R. Herrero, S. Askins, G. Sala, Jpn. J. Appl. Phys. 51, 10ND11 (2012).

[6] T. Minemoto, S. Nagae, H. Takakura, Sol. Energy 91, 919 (2007). 